Portland State University

PDXScholar

\title{
"How to Banish a Demon" : An Attempt to Present Traditional Japanese Theater to an American Audience with an Original Kyogen Play
}

Chrys Chabot

Portland State University

Follow this and additional works at: https://pdxscholar.library.pdx.edu/honorstheses

Let us know how access to this document benefits you.

Recommended Citation

Chabot, Chrys, "'How to Banish a Demon" : An Attempt to Present Traditional Japanese Theater to an American Audience with an Original Kyogen Play" (2015). University Honors Theses. Paper 324.

https://doi.org/10.15760/honors.301

This Thesis is brought to you for free and open access. It has been accepted for inclusion in University Honors Theses by an authorized administrator of PDXScholar. Please contact us if we can make this document more accessible: pdxscholar@pdx.edu. 
"How to Banish a Demon": An Attempt to Present Traditional Japanese Theater to an American Audience with an Original Kyogen Play

\title{
Chrys Chabot
}

\begin{abstract}
An undergraduate honors thesis submitted in partial fulfillment of the requirements for the degree of Bachelors of Science in University Honors and the Department of Theater with a Japanese minor
\end{abstract}

Thesis Advisor

Laurence Kominz

Portland State University 
Whether it makes you laugh, cry, or question your preconceived notions on a subject, the main point of any theatrical production is entertainment. The question then becomes, what is entertaining, and can a theatrical form that is over seven hundred years old from ancient Japan effectively entertain a modern American audience? More over, how to create a piece of theater that entertains its target audience while still remaining true to the original art form and the respectful to the culture that created it? To answer this I will examine two things using script analysis of existing kyogen plays: 1) what makes a kyogen a kyogen, and 2) what aspects of kyogen plays would best resonate with my prospective audience. I attempted to answer these questions through a creative process where, after intense script analysis of existing kyogen plays, I wrote an original kyogen, entitled How to Banish a Demon, which attempted to keep the core aspects of traditional kyogen intact, while at the same time being approachable by my target audience. I have cast a team of five wonderful actors from both PSU's theater and Japanese department to help me stage my production, which will be seen on June first as part of the Japanese department's Dance! Drama! Drums! event that features the work of the traditional Japanese drama class and the taiko drum club.

"Kyogen," which translates as "mad words," began in the fourteenth century as a counterpart to noh theater. Noh, which stems from the Sino-Japanese word for "skill" or "talent" is the oldest from of theater still practiced today. While the form we are familiar with now originated in the fourteenth century, it has roots dating back to the eighth century when forms of theatrical dance made their way from China. Kyogens are short plays, averaging ten minutes in length. They are a brief comedic interlude between heavy noh plays, satirizing noh plays, Shinto rituals, and Japanese folklore. 
Kyogen plays have been performed in almost the exact same manner for hundreds of years. There are paintings and woodblocks dating back to the early eighteenth century of one play in particular, Tsurigitsune (The Fox and the Trapper.) This play is perhaps the most important of a kyogen actor's repertoire and is performed as a rite of passage; it is akin to college thesis as it marks an actor's transition from student to professional. Pictured below is Tsurigitsume being performed in an early woodblock, again in the 1950s, and again in the 1990s.

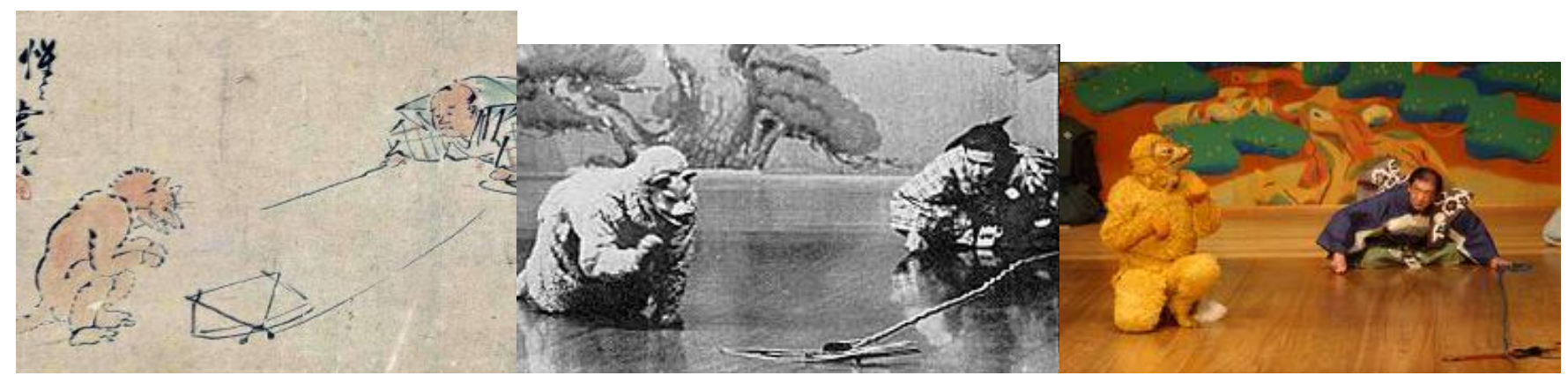

It was very important to me then to attempt to study these highly practiced movements as well as the actual scripts.

The first kyogens had no authors and no scripts. They were the physical embodiments of the Japanese oral tradition, displaying a comedic variant of stories of dear to the hearts of the audience. They belong not to a single named author, but to the Japanese people as a whole. Given the Western preoccupation with ownership, it is difficult to find a Western equivalent. Even our fairytales, which began as an oral tradition, are now attributed to the Brothers Grimm, who didn't author them, but merely collected and transcribed them. I found my equivalent in children's songs, something that everyone in the audience would know and relate to, but think of as a deep rooted part of their general culture, rather than the work of a single author. 
Luckily, I was not tasked with finding a traditional Japanese tale and a western children's song that could be seamlessly blended, as Japan had done that for me. I recalled a children's story from my childhood about the origins of the Japanese Setsubun Festival, a festival in which people throw roasted soy beans as a part of a ritual to banish demons. The versions of the origin story I has heard involved an old man who ate too many beans and got a horrible stomach ache. It an attempt to alleviate his stomach ache he swallows a bug, but then begins to crawl around like one. He then swallows a frog to catch the bug, and begins to act like a frog. This chain of events continues to escalate along the same vein, until it culminates in him swallowing a demon. The story ends with him swallowing some magic beans that cause him to expel all that he had swallowed, including the beans that had caused his original stomach ache. The old man's act of swallowing the intensifying chain of animals was uncannily reminiscent of the song The Old Woman Who Swallowed the Fly, and required almost no modification to serve the purpose of this project. The one major change I made to the tale was that instead of consuming magic beans to expel all that he had swallowed, they are pulled out by his concerned wife, and the act of vomiting the beans in a shower upon the demon is what drives him away.

Kyogen developed at the same time as the Italian commedia dell'arte, and has many similarities to its European counterpart. Most notable is its use of stock characters, usually a pairing that turns a typical power dynamic on its head. In both, this is often a foolish master and a clever servant or an oafish husband and the wife who deals with him. Such pairings continue to be prevalent in modern comedy, the latter being central to the plot of successful sitcoms all over the world. Again the tale I chose fits well into this category, with the majority of the action actually being driven by the two main supporting characters, rather than the old man. For in this story, when the old man initially becomes ill, his wife, the "straight man" of the tale, runs to get 
the advice of wise mountain priest, it is he that tells he that he needs to swallow the animals, which by the end results is the following advice, "Hmm. . I know! And this is my last plan. An oni (the Japanese word for demon)! The oni will devour the hunter that shot the bird that caught the snake that swallowed the frog that gulped down the bug that nibbled the beans!"

Another notable feature of kyogen is the use of onomatopoeia. Most props in kyogen are pantomimed, and characters often vocalize their interactions with them. For instance, a burglar trying to break a lock with a stone may say the equivalent of "Bang!" when he strikes it. And actors portraying animals will often the onomatopoeia associated with the animal. This would be like a Western actor playing a dog actually saying the word "Woof!" rather than make an unintelligible barking noise. While it is hard to find too many examples of this in American pop culture, there is irrefutable anecdotal evidence. Go down any toy aisle selling Star Wars toys and you won't have to wait long for someone, or any age, to begin strike a pose and start making the familiar whooshing noise. Likewise, hand two children a pair of toy guns, if they are revolvers, then children will begin to yell "Bang! Bang!", but if they are futuristic weapons, they will begin to yell "Pew! Pew! Pew!"

I kept this as intact as much as possible, using not only the concept but the actual Japanese language as well. Every time the old man takes on the characteristics of one of the things he has swallowed, he demonstrates this not only with a physical action, but with the associated Japanese onomatopoeia. For instance, when the old man swallows a bird and begins to try and fly about the stage, when he flaps his arms we shout, "Basa! Basa!" ,which is the Japanese onomatopoeia for the sound of flapping. When the old man swallows a hunter and begins to march about, he does it to the line "Taka taka taka," or the sound of marching. 
Kyogens rely heavily on physical comedy. Kyogen characters trip, tumble, exchange exaggerated blows, portray anthropomorphic animals, both clever and foolish, dance wildly, and a host of other things. This plays well with America's love of slapstick comedy, as seen by the continued popularity of the Three Stooges, America's Funniest Home Videos, and, most recently, the Jackass franchise.

Other than the onomatopoeia, the old man has only two lines in my play, one at the beginning, and one at the end for the sake of continuity. For the rest of the play, his performance is carried entirely on the strength of his physical actions. It was so important, that for the first two rehearsals, all five of my actors did nothing but workshop different interpretations of his animal roles. This allowed the actor playing the old man not only to brainstorm potential interpretations with his fellow actors, but allowed him to study in depth their movements so that he might better perform them.

Other notable features of kyogen theatre are the use of stock phrase or gestures, little bits of repeated business that appear throughout the play and often appear in many different kyogen plays. Lines are often delivered in a rhythmic, lyrical, or sing-song manner.

Also without many lines in my play is the character of the demon. While he doesn't have lines, he does have a very particular way of moving. His feet are heavy, making use of the spring-like quality of both our and traditional noh stages. His knees are always slightly bent giving him a bowed and intimidating appearance. His arms are also held at a particular angle, and he enters the stage with a series of stomps reserved in kyogen for demons and gods. His one line is a stock phase in Japanese reserved for actors playing demons. 
Costumes in kyogen plays are generally some variant of kamishimo, an Edo period outfit that consists of kataginu, a vest like garment, and hakama, a kind of traditional pleated pant, over a kimono. Lord and master characters will often wear nagabakuma, a long, trailing variant of hakama. Alternative costumes are worn by religious figures, animals, women, and other special characters. Women characters, such as the old man's wife wear long wrapped turbans in white to simulate a woman's long hair. Demons and gods have the most elaborate costumes, costumes that most resemble their noh counterpart.

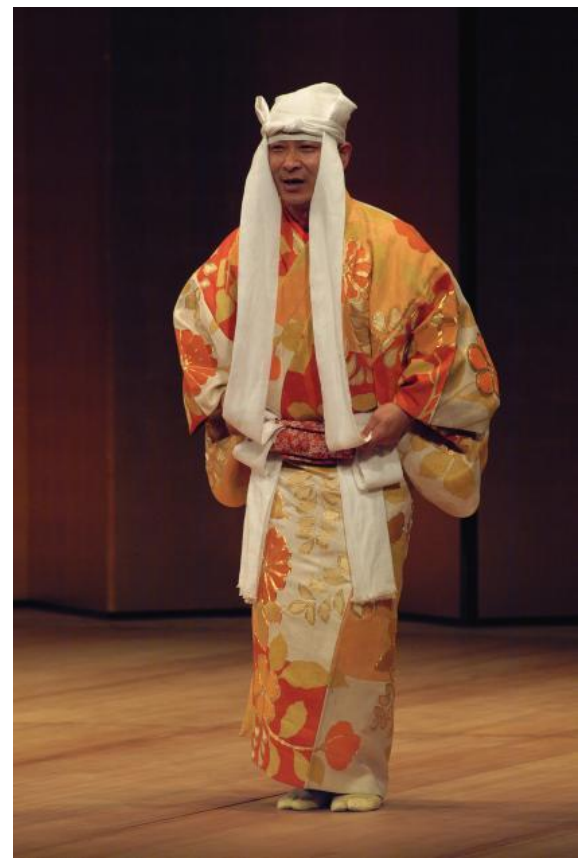

Images:

(Left) Actor playing a woman in a kyogen

(Bottom Left) Actor playing a demon in a kyogen

(Bottom Right) Actor playing a demon in a noh 

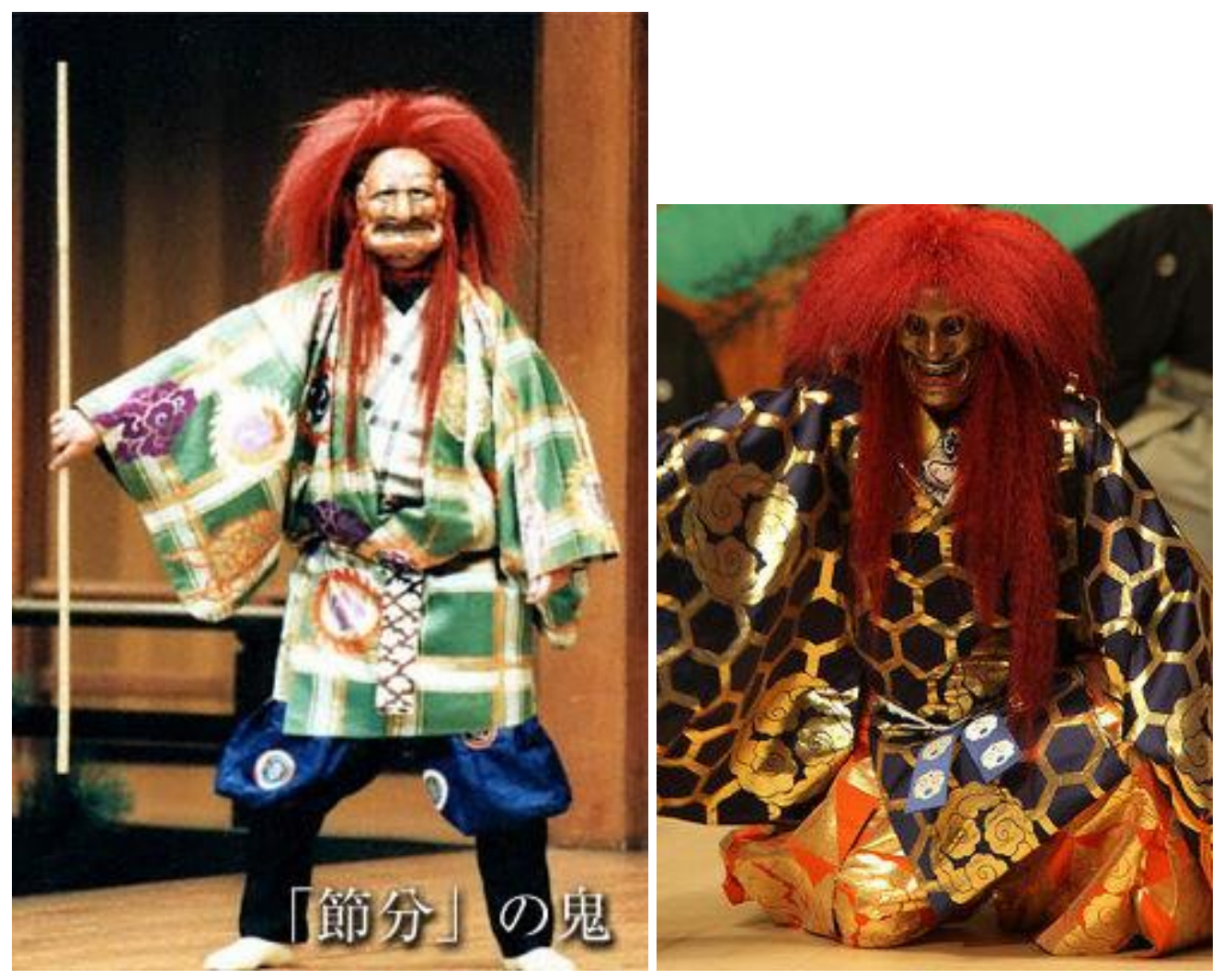

I have attempted throughout the scripting and staging of my new kyogen, to respect and embody the aspects of the original art form that makes it what it is and have given it the power to entertain across generations and national boundaries. It is my sincerest hope that those who view it will recognize it as deferential and respectfully cultivated attempt to introduce a wider audience to this beloved theatrical form. 